
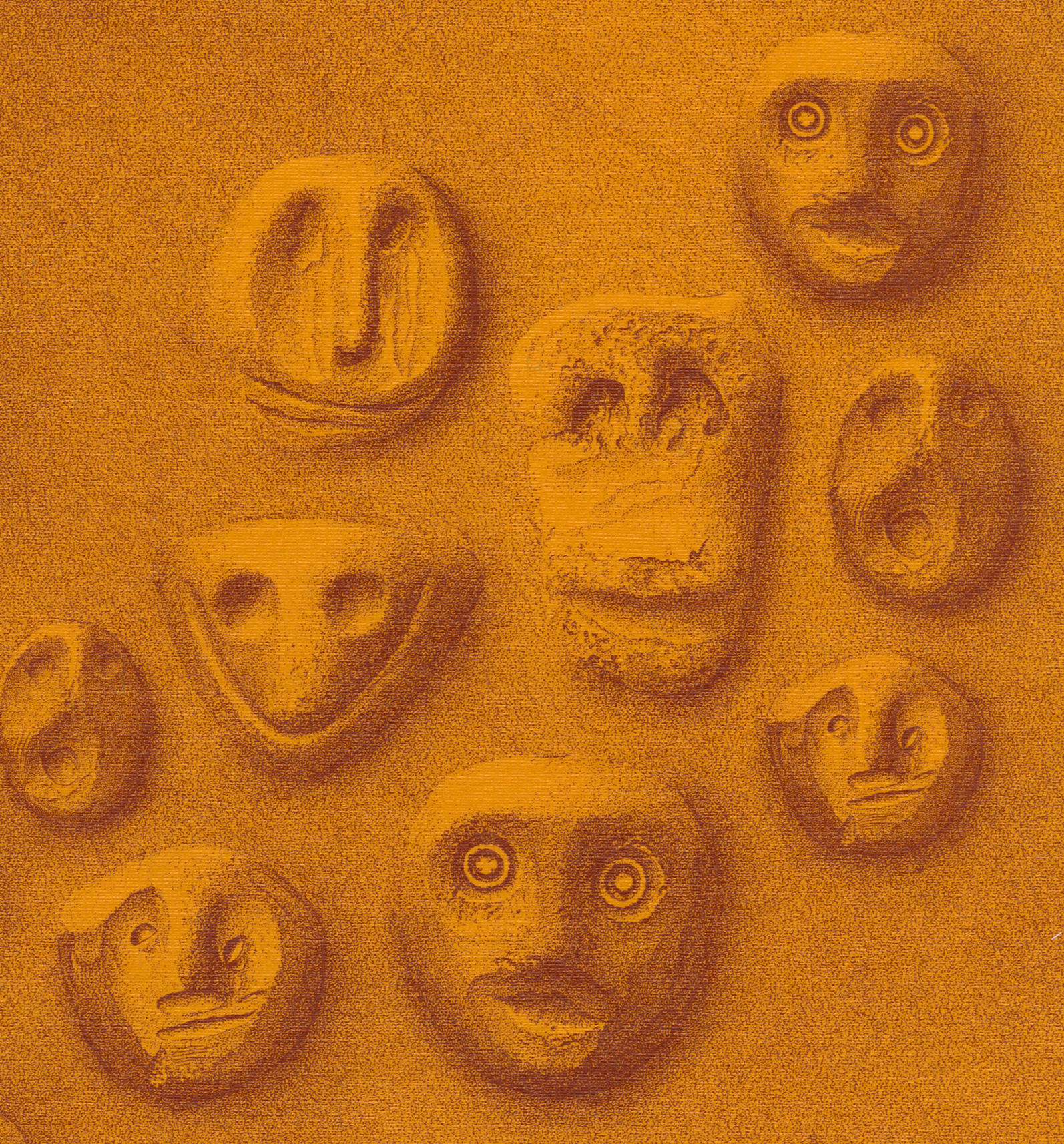

5) - Nethe

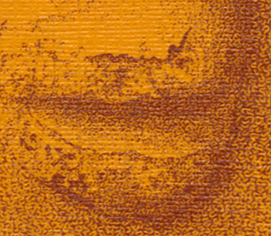




\section{KUML 1990}

Årbog for Jysk Arkæologisk Selskab

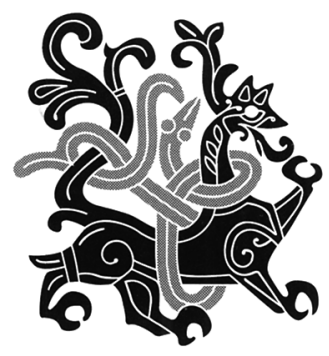

With summaries in English

I kommission hos Aarhus Universitetsforlag, Århus 
Redaktion: Poul Kjarum

Redaktionsudvalg:

Jens Henrik Bech, Thisted

Steen Hvass, Vejle

Stig Jensen, Ribe

Erik Johansen, Aalborg

Erik Jorgensen, Haderslev

Hans Jorgen Madsen, Arhus

Omslag: Lerhoveder fra celdre jernalder

Udgivet med stotte af Statens Humanistiske Forskningsråd

Omslag: Jens Kirkeby

Grafisk tilretteloggelse: Elsebet Morville

Tryk: Special-Trykkeriet Viborg a-s

Skrift: Bembo 11/12

Papir: Stora G-Print $120 \mathrm{~g}$

Copyright 1992 by Jysk Arkceologisk Selskab

ISBN 87-7288-562-9

ISSN 0454-6245 


\section{Indhold/Contents}

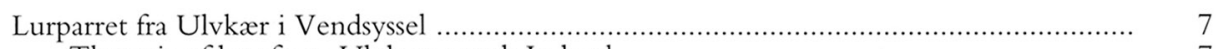

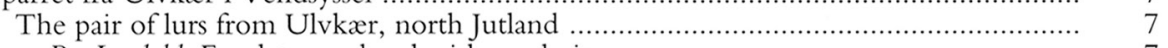

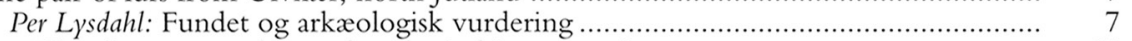

The discovery and its archaeological interpretation ................................. 21

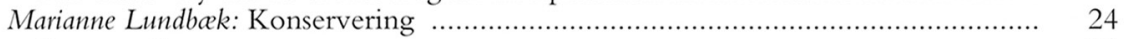

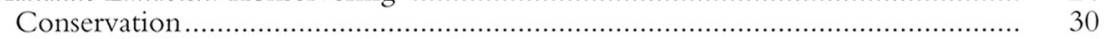

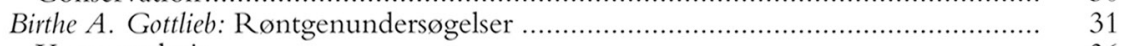

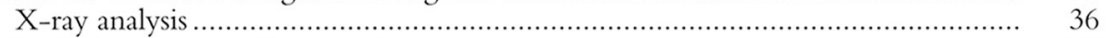

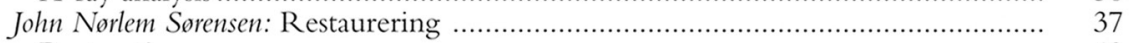

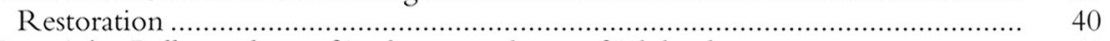

Bent Aaby: Pollenanalyser af jordprøver udtaget af Ulvkærlurerne ............................. 41

Pollen analysis of peat samples from the Ulvkær lurs .............................. 42

Erik Johansen: En brandgravplads med smykkefund fra førromersk jernalder.................... 45

A cremation cemetery with ornaments from the pre-Roman Iron Age ...................... 56

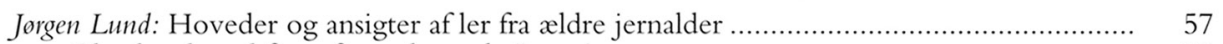

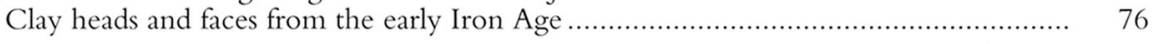

Lise Bender Jørgensen: Hørvævninger og oldtidsvæve ......................................... 77

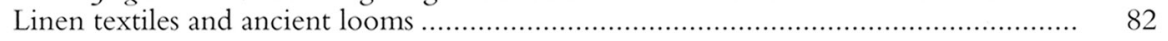

Per Ethelberg: To grave fra Højvang, Sønderjylland .............................................. 85

Dendrodatering og absolut kronologi

Two graves from Højvang in southern Jutland; dendrodating and

absolute chronology

John Brinch Bertelsen: Nederby på Fur - en landsby grundlagt i yngre jernalder

Et bidrag til belysning af vikingetidsbebyggelsen i den vestlige del af Limfjorden ........

Nederby on Fur, a village founded in the later Iron Age. A contribution to

knowledge of Viking settlement in the western Limfjord

Torben Nilsson: Stentinget. En indlandsbebyggelse med handel og håndværk fra

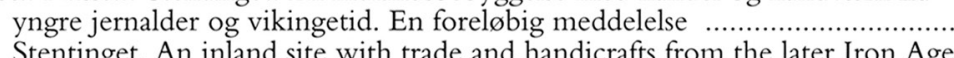

Stentinget. An inland site with trade and handicrafts from the later Iron Age.

A preliminary notice.

H. J. Madsen og Per Vegger: Karby på Mors. En landsby fra vikingetiden

Karby on Mors, a Viking village ....

En vikingetidssølvskat fra Brokhøj, Gjerrild Klint

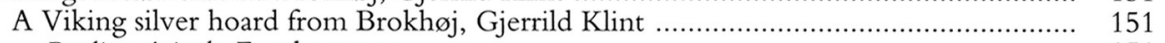

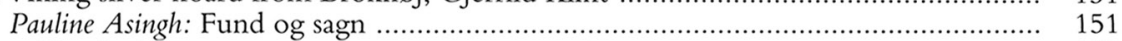

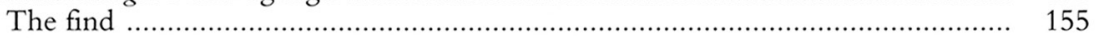

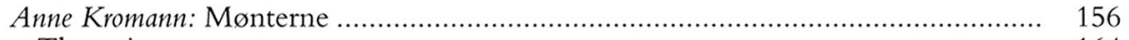

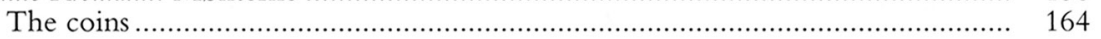




\title{
En vikingetidssølvskat fra Brokhøj, Gjerrild Klint
}

\author{
Af Pauline Asingh og Anne Kromann
}

\section{Fund og sagn}

"Der er flere høje, der hedder Brokhøje ude efter Havet på Gjerrild Mark lidt nordøst for Stokkebro, og der var Dwarre (dværge). En kunne se dem gaa og pusle der til visse Tider, og de gik og bar Byldter ned i den største Høj. På den Høj var også to Stenovne.« (1).

Sådan lyder en af folkemindesamleren Evald Tang Kristensens optegnelser fra forrige århundrede.

Som navnet angiver har disse høje været hjemsted for grævlinge. Deres tilstedeværelse, og især senere tiders stenplyndringer og opdyrkning har efterhånden bevirket, at højene er blevet så godt som jævnet med jorden. De sidste rester af den største af Brokhøjene, netop den, der ifølge Nationalmuseets sognebeskrivelse endnu i 1880-erne rummede to dyssekamre, var i 1986 truet af total nedpløjning, og derfor iværksatte Djurslands Museum en udgravning på stedet (2). Uden iøvrigt at gøre sig forhåbninger om at nå til en afklaring af, hvad det var for nogle bylter, dværgene gik og bar ned i højen.

\section{Undersøgelsen}

Pløjelaget blev afrømmet med maskine, og snart sås sporene efter en ganske anseelig langdysse, $18 \mathrm{~m}$ lang, $8 \mathrm{~m}$ bred og med to stensatte gravkamre (fig. 1). Såvel kammerstenene som kæden af randsten, som har omgivet højen, var for længst sprængt bort og fjernet, lige med undtagelse af en af de store kammersten, som lå væltet og delvist sprængt bag det vestlige kammer.

På trods af de mange ødelæggelser, som langdyssen gennem tiderne har været udsat for, var sporene efter de sprængte sten til alt held stadig at se i undergrunden som muldfyldte huller med granitskærver, og højens oprindelige grundplan kunne så nogenlunde bedømmes.

De to gravkamre har udvendig målt omkring $4 \times 4 \mathrm{~m}$, og har sandsynligvis haft åbning mod syd, hvor der var spor efter indgangspartier. Foran lå rester af de ofrede lerkar sønderknust, sammen med brudstykker af slebne flintøkser og ravperler, som efter alt at dømme var udrømmet fra gravkamrene.

Randstenene, som i et rektangulært forløb har omgivet højen, har stået ganske tæt side om side og været af betydelig størrelse. Især de østlige gavlsten, med en diameter på over en meter.

Med afdækningen af stenspor efter stenspor, genskabtes efterhånden billedet af den langdysse som dværgene ifølge sagnet bar bylter ned i. Men hvad var der 


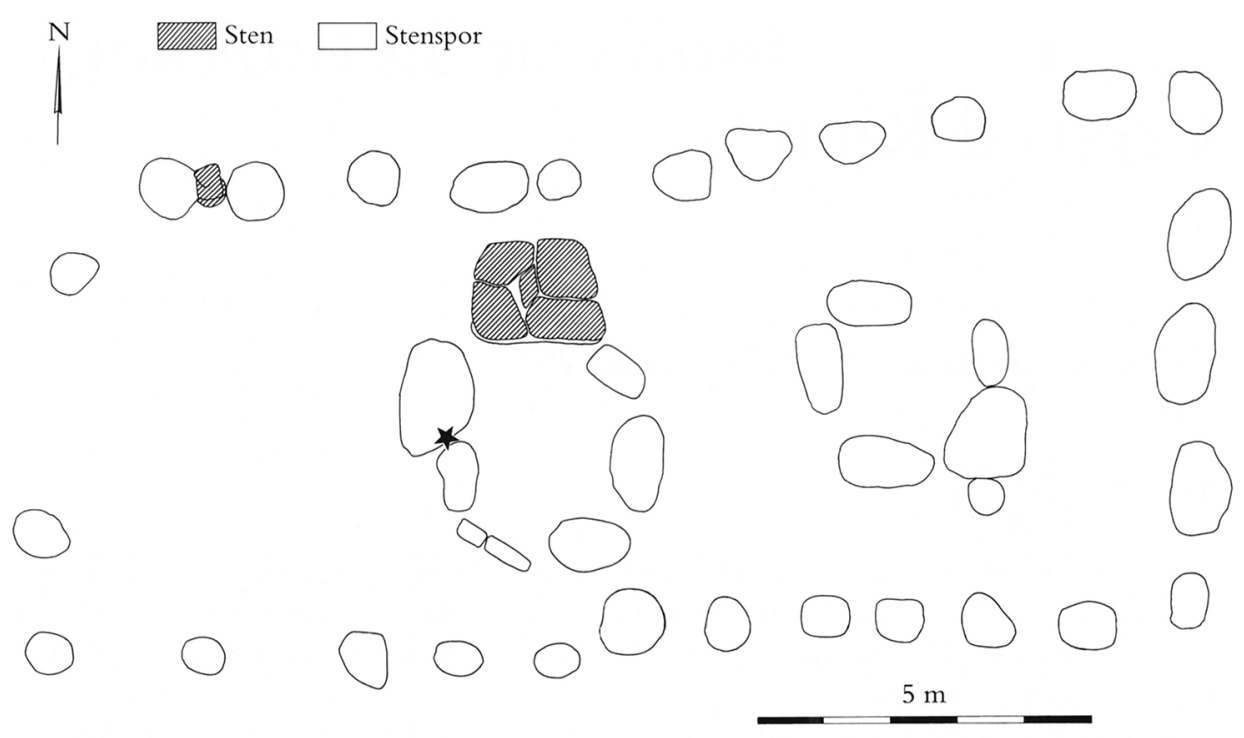

Fig. 1. Langdyssens grundplan med angivelse af findested for sølvskatten.

Plan of the long mound, showing the place where the silver hoard was found.

så i disse bylter? En skat, vil svaret sandsynligvis lyde, hvis vi går til de gamle folkeoverleveringer.

Og ganske rigtigt dukkede der i et stenspor i det vestlige gravkammer en lille, hvidgrå, flad genstand op, som ved nærmere eftersyn viste sig at være en mønt fra vikingetid. Og der kom mere. I udkanten af samme stenspor lå 9 brudstykker af mønter og ringe, alt i sølv, og tæt herved, et større fragment af et lerkar, formodentlig fra en beholder skatten har været nedsat i (fig. 2). Sølvstykkerne lå i toppen af stensporet indenfor et $10 \times 25 \mathrm{~cm}$ stort område. Der er utvivlsomt tale om en af vikingetidens brudsølvskatte. Skatten har efter alt at dømme været gravet ned tæt ved den ene af kammerets bæresten. Ved sprængningen af kammerstenene er skatten røget med og sølvstykkerne er væltet ned i hullet efter den sprængte sten. Spørgsmålet var nu, om de 9 sølvstykker udgjorde hele skatten. Var der mere, måtte det ligge i dyngerne af pløjejord, som gravemaskinen havde gravet af området over dyssekammeret. Og ganske rigtigt. Efter en grundig gennemsøgning med metaldetektor, talte skatten 81 stykker sølv, nemlig 66 mønter og møntfragmenter og 15 brudstykker af især ringe og

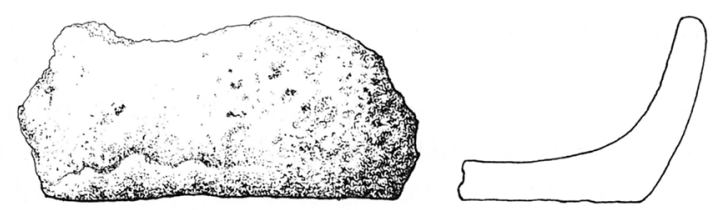

Fig. 2. Fragment af lerkar, fundet i stenspor nær brudsølv.

Fragment of a pot, found in an extraction hole near the scrap silver. 


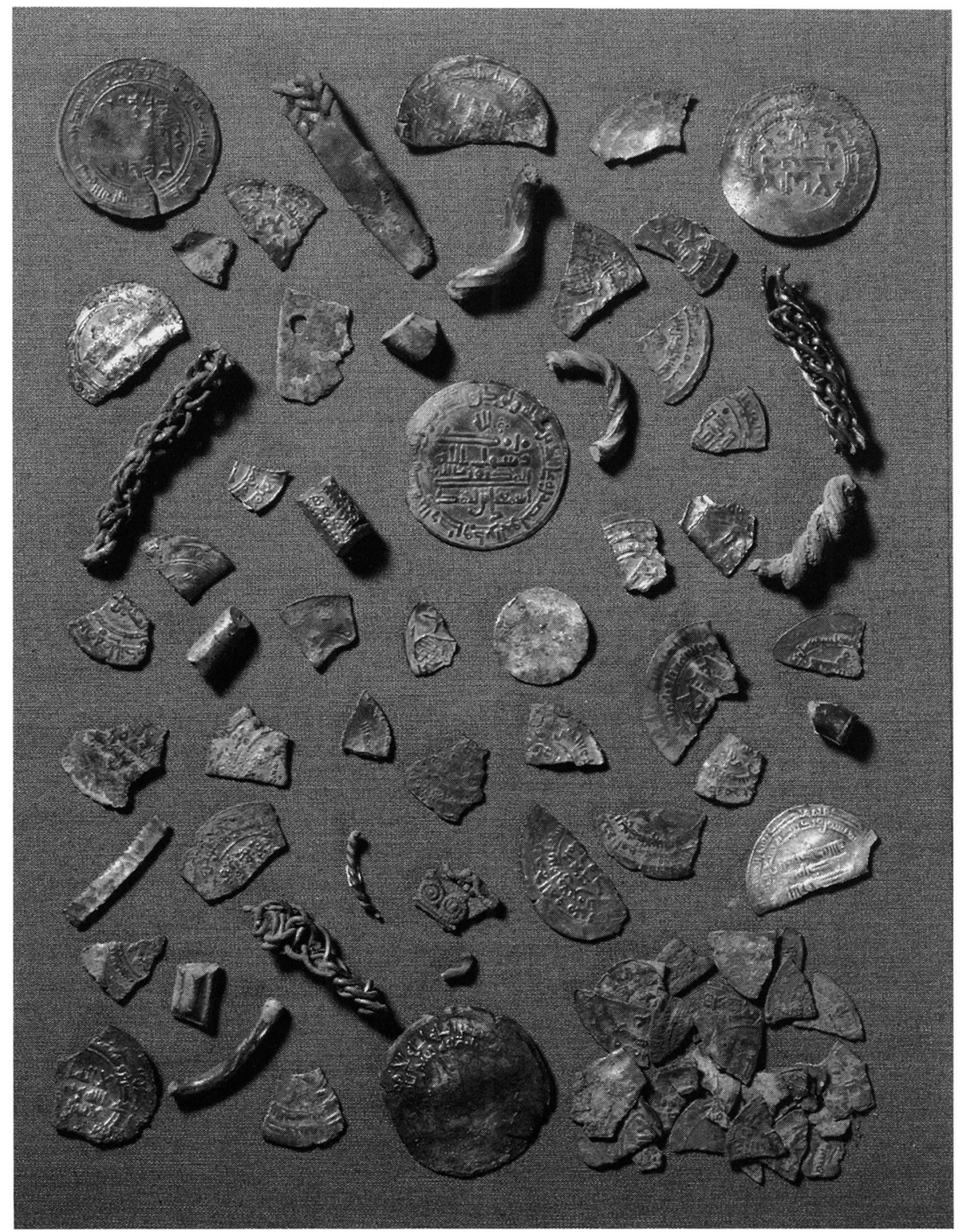

Fig. 3. Det samlede sølvfund. Foto: Lennart Larsen.

The complete silver find. Photo: Lennart Larsen.

barrer (fig. 3). For en halv snes år siden blev der ved højen desuden fundet en snoet ring med samme matgrå overflade som de ukonserverede sølvstykker. Det har antagelig været en snoet sølvring af samme slags, som man kender dem fra andre af vikingetidens skattefund. Men da den for finderen mest af alt lignede en tyrering, røg den ud over kanten af Gjerrild Klint sammen med et læs opsamlede marksten. 


\section{Gravhøje og skattefund}

Vikingetidens nedgravede skatte har givet anledning til mange diskussioner. De fleste hælder til den teori, at brudsølvskattene gemt på let genkendelige steder er rene værdidepoter (3). Har man ønsket at sikre sin opsparede kapital, var jorden et af de sikreste gemmesteder og tilsyneladende i særdeleshed oldtidens gravhøje. Faktisk er der indberetninger om fund af skatte fra vikingetid, middelalder og nyere tid fra rundt regnet et halvt hundrede gravhøje og højdedrag (4). Det berettes om flere fund, at der gentagne gange er pløjet sølvmønter eller ringe op på samme høj. I andre tilfælde er man ved næsten bortpløjede høje stødt på lerkar med hele eller sønderbrudte mønter og smykker, eller skatten er fundet, hvor der tidligere har ligget en høj. Atter andre er fremkommet ved, at man har villet fjerne en høj. Eksempelvis blev en vikingetidssølvskat fundet ved Sørbymagle på Sydvestsjælland, da en gårdmand var ved at fjerne en stendysse på sin mark (5). Skatten var, ligesom tilfældet var ved Brokhøj, sat ned mellem to store sten.

Egentlig har det været kendt gennem århundreder, at der ligger skatte gemt i vore gravhøje. Hvis vi skal tro de gamle folkeoverleveringer kan gravhøjene foruden kæmpegrave, trolde, dværge samt andet godtfolk, også rumme enorme skatte. En nedgravet skat røber sig ofte ved, at der ved nattetide brænder lys over højen, eller ved, at forbifarende hører kistelåg smække eller mønter klirre. Andre har set de rige højfolk gå og pusle omkring højen. Det var imidlertid ikke så ligetil at erhverve sig højfolkenes rigdomme, hvis vi skal dømme efter folkesagnenes mangfoldige beretninger om uheldsvangre skattegravninger. Gentagne gange berettes der om, at lige idet skatten, efter stort besvær, fremdrages, bryder alverdens ulyker ud, og underjordiske væsener dukker op, førend højen lukker sig om skatten for næsen af de skuffede skattejægere (6).

Fælles for de fleste af sagnene er de mytiske forestillinger, som højene og deres indhold er omgærdet med, og i vore øjne forbliver de eventyrlige fortællinger. Men de kan dog meget vel indeholde en kærne af sandhed, som genfortalt gennem generationer og krydret med folkelig overtro efterhånden har antaget eventyrlig form (7).

I andre overleveringer, som er blottet for eventyrligt præg, fortælles da også mere nøgternt om højfundne skatte (8). Ofte omtales såvel den lykkelige finder som fundstedet ved navns nævnelse. Det fremgår af beskrivelserne, at der næsten udelukkende er tale om møntfund. Til disse, efter alt at dømme historisk funderede overleveringer, knytter sig desuden adskillige, som beretter om skatte fundet i bakker, klinter eller under større sten. Det drejer sig sandsynligvis i mange tilfælde om fund fra ødelagte gravhøje og storstensgrave.

Sagnet fra Brokhøj hører så afgjort til kategorien af eventyrlige skattesagn, men er samtidig med til at understrege, at sagnene kan rumme et gran af sandhed. 


\section{NOTER}

1) Kristensen, E. T.: I)anske Sagn I. Ny rakke 1928. (On Bjærgfolk, man har set eller hort. s. 15f, nr. 49.

2) DJM 1995 (ijerrild Klint, Gjerrild sogn, Djurs Nr. herred, gl. Randers amt.

3) Bendixen, K.: Monternes vidnesbyrd. Numismatik - arkæologi - historie. Fra Holbæk amt 1976. s. 28ff. Hårdh, B.. Trade and Money in Scandinavia in the Viking age. Meddelanden från Lunds Universitets Historiska Museum 1978. Skovmand, R.: I)e danske skattefund fra vikingetiden og den æeldste middelalder indtil omkring 115(). Aarb. for Nord. (Oldk. og Hist. 1942. s. 183ff.

4) Skovmand, R.: I) danske skattefund fra vikingetiden og den aldste middelalder indtil omkring 1150. Aarb. for Nord. (Oldk. og Hist. 1942, og ifolge Nationalmuseets sognebeskrivelse, jvf. I)et Kulturhistoriske Centralregisters sogning på diverse stikord.

5) Skovmand, R. 1942. s. 8f, nr. 47. Bjodstrup, Sorbymagle sogn, V. Flakkebjerg herred.

6) Grundtvig, S.: I)anske Folkesagn 1839-83, bd. 1-2. V. Ellekilde, H. 1946-48. Kristensen, E. T.: I)anske Sagn III 1895. Piø, I.: Hojfolkets guld. Jorgensen, M. S. (red.): (iuld fra Nordvestsjæelland 1975.

7) Pio, I.: Sagn som sandhedskilde. Fra Holbak amt 1976, s. $151 \mathrm{ff}$.

8) Kristensen, E. T. 1895: Blandt andre sagnene nr. 429, 2210, 2215, 2198, 2209, 2213, 2220.

\section{A Viking Silver Hoard from Brokhøj, Gjerrild Klint}

\section{The find}

In 1986 1)jursland's Museum excavated the remains of a much ploughed down megalithic long-mound at Gjerrild Mark in northern Djursland. The stones of the dolmen and the uprights of the peristalith had nearly all been blown up and removed. Marks in the subsoil surface where the stones had stood made it possible to establish most of the plan of the monument, which had been $18 \mathrm{~m}$ long and 8 mide with 2 stone chambers.

In an extraction hole of the western dolmen lay 10 fragments of coins and rings, all of silver, with close to them a fragment of a pot. This was undoubtedly a Viking silver hoard, which had presumably been inserted in the ground close to one of the uprights of the chamber and had been disturbed when this had been blown up. After a thorough search through the dump of ploughsoil from over the chamber, the hoard came up to 81 pieces of silver, of which 66 were coins and 15 fragments of rings and ingots.
Pauline Asingh

Ebeltoft Museum

Oversattelse: David Liversage 